\title{
A KALLMAN-ROTA INEQUALITY FOR EVOLUTION SEMIGROUPS
}

\author{
C. Buşe AND S. S. Dragomir
}

Abstract. A Kallman-Rota type inequality for evolution semigroups and applications for real valued functions are given.

Mathematics subject classification (2000): 47A30.

Key words and phrases: Kallman-Rota inequality, evolution semigroups.

\section{REFERENCES}

[1] C. Chicone, Yu. LATUSHKIN, "Evolution Semigroups in Dynamical Systems and Differential Equations", Amer. Math. Soc., Math. Surv. and Monographs, 70, 1999.

[2] S. Clark, Yu. Latushinin, S. Montgomery-Smith and T. Randolph, Stability radius and internal versus external stability in Banach spaces: An evolution semigroup approach, SIAM J. Contr. and Optim., 38 (2000), 1757-1793.

[3] K. ENGEL AND R. NAGEL, "One-parameter semigroups for linear evolution equations", Springer-Verlag, New York, 2000.

[4] R. R. Kallman and G. C. Rota, On the inequality $\left\|f^{\prime}\right\| \leqslant 4\|f\|\left\|f^{\prime \prime}\right\|$, Inequalities II, O. Shisha, Ed., Academic Press, New York, 1970, pp. 187-192.

[5] Yu. Latushin and S. MonTGOMERY-Smith, Evolutionary semigroups and Lyapunov theorems in Banach spaces, J. Func. Anal., 127 (1995), 173-197.

[6] B. M. LeVitan And V. V. ZhiKov, "Almost Periodic Functions and Differential Equations", Moscow Univ. Publ. House, 1978. English translation by Cambridge Univ. Press, Cambridge U.K., 1982.

[7] NGUYen VAn Minh, FranK RÄBIGER AND Roland ScHNAUbelt, Exponential stability, exponential expansiveness, and exponential dichotomy of evolution equations on the half-line, Integral Equations Operator Theory, 32 (1998), 332-353.

[8] T. NAITO, NGUYEN VAN MinH, Evolution semigroups and spectral criteria for almost periodic solutions of periodic evolution equations, J. Differential Equations, 152 (1999), 338-376.

[9] R. RAU, Hyperbolic evolution semigroups on vector valued-functions, Semigroup Forum, 48 (1994), 107-118. 